\title{
Effects of chemical climate on soil depth distribution and plant uptake of radiocaesium in forest ecosystems
}

\author{
H. Thørring ${ }^{1}$, L. Skuterud ${ }^{1}$ and E. Steinnes ${ }^{2}$ \\ ${ }^{1}$ Norwegian Radiation Protection Authority, P.O. Box 55, NO-1332 Østerås, Norway \\ ${ }^{2}$ Department of Chemistry, Norwegian University of Science and Technology, \\ NO-7491 Trondheim, Norway
}

\begin{abstract}
The aim of the present work was to study the impact of chemical climate (i.e. the chemical composition of precipitation) on radioactive caesium in soil and plants. This was done through field studies and a laboratory experiment. Three types of precipitation regimes were considered in both cases, representing a natural range found in Norway: Acidic precipitation (southernmost part of the country); precipitation rich in marine cations (coastal areas); and low concentrations of sea salts (inland areas). Results indicate that acid rain increases the mobility and the plant availability of radioactive caesium.
\end{abstract}

\section{INTRODUCTION}

Precipitation may be an important source of mobile ions in natural surface soils [1]. Previous studies in Norway have indicated that retention of radioactive caesium in surface soils is influenced by geographical variations in the composition of precipitation [2,3], and it is well known that concentrations of mobile base cations can influence plant availability of radionuclides. The aim of the present work was to study the impact of chemical climate (i.e. the composition of precipitation) on radioactive caesium in soil and plants in more detail. The study was divided in two main parts: (1) Field studies from bilberry birch forests sites subject to different chemical climate; (2) Soil column studies performed in the laboratory. In both parts three types of precipitation regimes were considered, representing a natural range found in Norway: Acidic precipitation, precipitation rich in marine cations, and low concentrations of sea salts.

\section{FIELD STUDIES}

Soil and plant samples were collected in four regions of Norway subject to climatic conditions ranging from highly oceanic to slightly continental, and exposed to different levels of long-range atmospheric deposition of air pollutants. The geographical location of the sampling areas - denoted A, B, C and D - are shown in Figure 1. Different ranges of marine influence are indicated by chloride deposition [4], and influence of long-range transported pollutants from other parts of Europe by lead concentration in terrestrial moss [5]. Three representative sites were selected within each of the four study areas. An overview of the treatment and analyses of field samples is shown in Figure 2.

\subsection{Caesium-137 in soil}

Deposition density estimates with depth distributions are shown in Figure 3. In general the ${ }^{137} \mathrm{Cs}$ contamination was markedly higher in area $\mathrm{C}$ compared with the other areas, which is in accordance with the Chernobyl deposition pattern in Norway [6]. There is also a significantly higher retention of total caesium-137 in the top $0-3 \mathrm{~cm}$ soil layer of area $\mathrm{C}$ than in the other areas (ANOVA, $p<0.01$ ). 


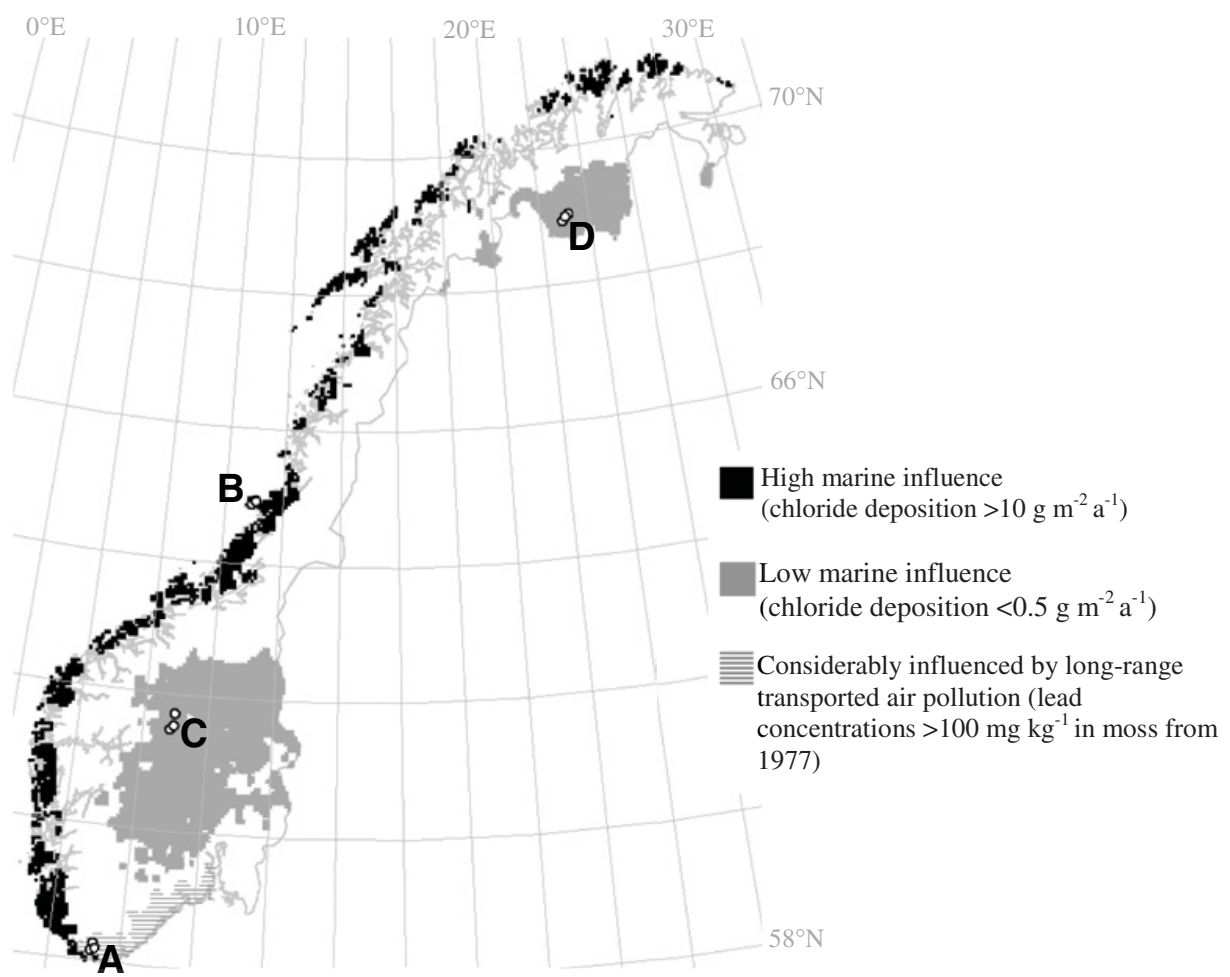

Figure 1. Map of Norway indicating study sites and (simplified) information regarding regional variation in composition of precipitation.

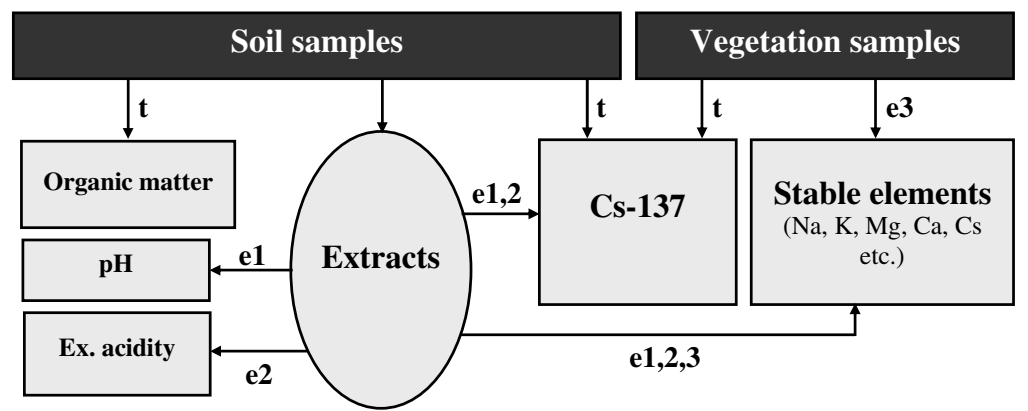

Figure 2. Overview of treatment and analyses of field samples $(t=$ total, e1 $=$ water extract (soluble fraction), $\mathrm{e} 2=$ ammonium nitrate extract (exchangeable fraction), $\mathrm{e} 3=$ nitric acid digest (acid soluble fraction).

Obviously the depth distribution of caesium-137 shown in Figure 3 is not due to precipitation quality alone. There are considerable differences in soil composition between the coastal areas $(\mathrm{A}+\mathrm{B})$ on one side and inland areas $(\mathrm{C}+\mathrm{D})$ on the other: The coastal sites have a generally thick organic layer $(6-12 \mathrm{~cm})$, with LOI around $90 \%$, whereas the corresponding layers at the inland sites are significantly thinner, with a considerably higher mineral content ( $50 \%$ or more). Furthermore, about $80 \%$ of the Cs137 in area $\mathrm{D}$ - in contrast to the other three areas - originates from the nuclear weapons tests in the 1950s and 60s [7], and the relatively low retention of caesium-137 in the uppermost layer may to some 

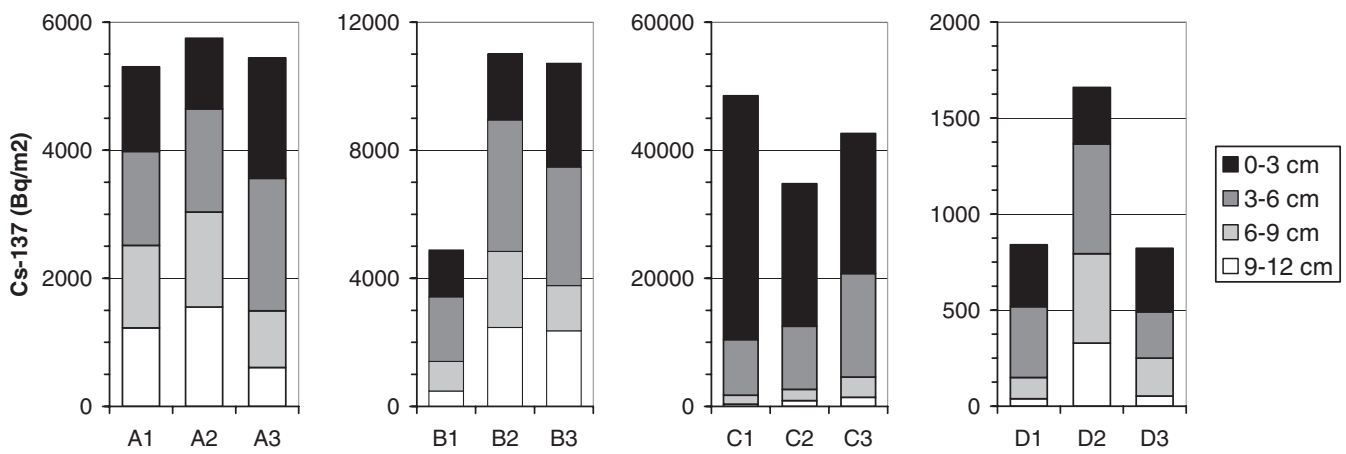

Figure 3. Total inventories $(0-12 \mathrm{~cm})$ of $\mathrm{Cs}-137$ at all study sites $\left(\mathrm{Bq} / \mathrm{m}^{2}\right)$ with depth distribution indicated by grey scale. Each study site is based on 3-4 soil profiles.

extent be attributable to the longer time passed since fallout. Consequently, vertical distribution at the D sites is not directly comparable to results from areas A-C.

In area $\mathrm{C}$, merely $1-8 \%$ of the humus layer ${ }^{137} \mathrm{Cs}$ was extracted using ammonium nitrate (e2), whereas the corresponding figures from the coastal areas were 30-40\% and 20\%, respectively. Furthermore, the exchangeable fraction was relatively high (20-30\%) in area D - in spite of the longer time since fallout. The most likely cause of the generally lower mobility of caesium-137 in area $\mathrm{C}$ compared with the other three sites is higher content in the soil of micaceous clay minerals such as illite, which specifically bind caesium [8].

From exchangeable fractions alone one should expect differences in vertical distribution between areas $\mathrm{A}$ and $\mathrm{B}$. Our results, however, do not indicate - in spite of the larger soluble/exchangeable fractions - a higher vertical mobility at the A sites. There may be several explanations to this, one important factor being recirculation of ${ }^{137} \mathrm{Cs}$ in the uppermost soil layer due to uptake in plants.

\subsection{Transfer of caesium-137 to plants}

Plant specific aggregated transfer factors $\left(\mathrm{T}_{a g} \mathrm{~s} ; 0-12 \mathrm{~cm}\right)$ were derived using relevant deposition densities from Figure 3. A summary of the results for the five plant species found at all 12 sites are shown in Figure 4. For these species, ANOVA (with post-hoc Tamhane T2) showed that soil-to-plant transfer was significantly higher in area A compared with the three other areas $(p<0.01)$. The $\mathrm{T}_{a g} \mathrm{~s}$ were also significantly higher in area $\mathrm{B}$ compared with area $\mathrm{C}(p<0.05)$, but not statistically different from the $\mathrm{T}_{a g} \mathrm{~S}$ in area $\mathrm{D}$.

As evident from Figure 4, the transfer factor was in average 7-8 times higher in area A compared to area $\mathrm{C}$. This difference, however, is smoothing out when considering the exchangeable fractions of ${ }^{137} \mathrm{Cs}$, and is apparently due to the low caesium mobility in area C. More interesting for our purpose is comparing the two coastal areas: Using the humus layer as a collective term for the layers $0-3,3-6$, and $6-9 \mathrm{~cm}$, a $t$-test showed that the $\mathrm{pH}$ and base saturation were significantly higher in area $\mathrm{B}(p<0.01)$, whereas the exchangeable acidity was significantly higher in area $\mathrm{A}(p<0.01)$. These differences are clearly attributable to different composition of precipitation between the two regions, and comprise a likely explanation to the lower transfer of soluble/exchangeable caesium-137 in area B.

\section{COLUMN STUDY}

Undisturbed soil profiles $(0-40 \mathrm{~cm})$ were gathered in the vicinity of the $\mathrm{C}$ sites sampled in the field study (Fig. 1). All profiles were podzols collected within a small area of approximately $2 \times 10 \mathrm{~m}$. In the laboratory 9 soil columns (Fig. 5) were treated with artificial precipitation of different composition: 


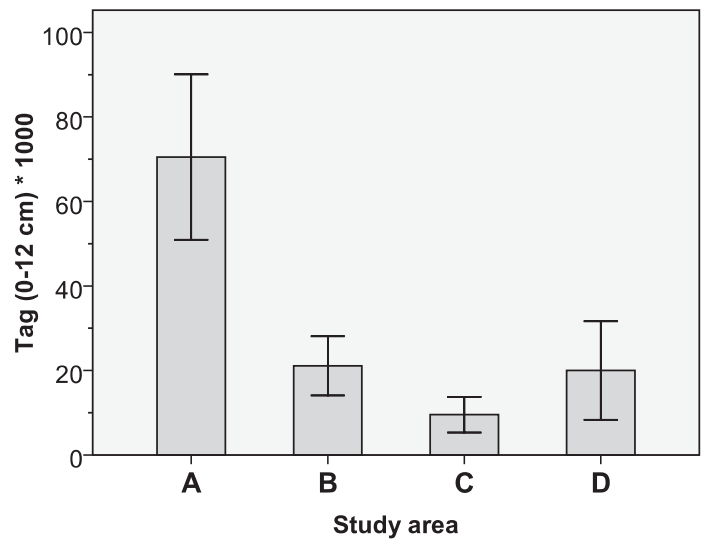

Figure 4. Arithmetic mean $( \pm 95 \% \mathrm{CI})$ of five plant species found at all 3 sampling sites for each study area A-D (Betula pubescens, Junipherus communis, Vaccinium myrtillus, Vaccinium vitis idaea, Deschampsia flexuosa).
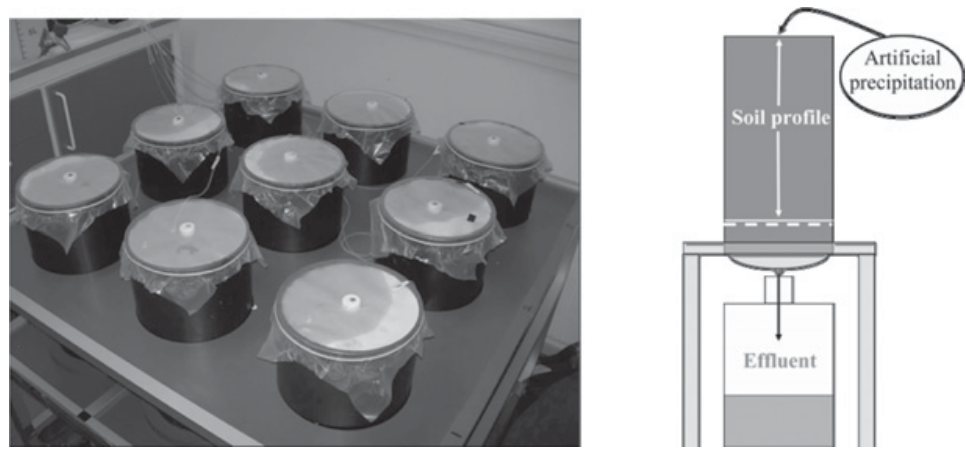

Figure 5. Study setup. Pump flow was $0.55 \pm 0.02 \mathrm{ml}$ per minute (i.e. $1.23 \mathrm{~mm} / \mathrm{h}$ ).

Three columns (Ac 1-3) were added acidic precipitation ( $\mathrm{pH}$ 4.2) with increased levels of ammonium, three were treated with precipitation rich in marine cations (Ma 1-3), while the last three were supplied with precipitation characteristic of inland areas, containing low concentrations of sea salts (In 1-3).

Following an equilibrium period of 12 weeks of continuous precipitation, ${ }^{134} \mathrm{Cs}(7000 \mathrm{~Bq})$ was added to all columns in order to investigate differences in mobility between "freshly added" radiocaesium (here represented by ${ }^{134} \mathrm{Cs}$ ) and "older" caesium-137 mainly from the Chernobyl accident, presumably more strongly fixed in the soil. The amount of artificial precipitation added during the whole period was approximately $10000 \mathrm{~mm}$. Effluent samples were taken at regular intervals (ca 3 times a month). Conductivity and $\mathrm{pH}$ were measured for all samples, whereas radiocaesium $\left({ }^{134} \mathrm{Cs},{ }^{137} \mathrm{Cs}\right)$ was determined in selected samples. Effluent activity concentrations above detection limits $(>1.5 \mathrm{~Bq} / \mathrm{l})$ were observed neither for ${ }^{137} \mathrm{Cs}$ nor for ${ }^{134} \mathrm{Cs}$. After the column setup was taken down the soil profiles were carefully sliced. $96 \pm 4 \%$ of the added caesium-134 was recovered in the soil cores.

\subsection{Depth distribution of radioactive caesium}

The results shown in Table 1 indicate that vertical distribution of "freshly added" radioactive Cs in soil is influenced by the composition of precipitation, and that acid rain (with low $\mathrm{pH}$ and high ammonium concentration) increases caesium mobility compared with the other two precipitation types used in the experiment. A likely cause for the higher mobility of freshly added caesium-134 for the columns treated with acid precipitation is competition with ammonium for frayed edge sites (FES). Moreover, an 
Table 1. Vertical distribution of ${ }^{134} \mathrm{Cs}(\%) 38$ weeks after addition of tracer. Tinted cells represent the humus layer and the gray scale indicates estimated organic matter content (from 20 to more than 90\%). The outlined soil depths contain minimum $95 \%$ of the activity.

\begin{tabular}{|c|c|c|c|c|c|c|c|c|c|}
\hline \multirow{2}{*}{$\begin{array}{c}\text { Depth } \\
(\mathrm{cm})\end{array}$} & \multicolumn{9}{|c|}{ Column } \\
\hline & Ac1 & Ac2 & Ac3 & Ma1 & Ma2 & Ma3 & In1 & In2 & In3 \\
\hline $0-2$ & 55.5 & 61.7 & 19.9 & 96.2 & 84.7 & 75.6 & 64.3 & 97.2 & 67.4 \\
\hline $2-4$ & 27.1 & 29.6 & 27.4 & 3.7 & 15.2 & 16.8 & 21.4 & 2.3 & 25.2 \\
\hline $4-6$ & 11.5 & 8.2 & 34.8 & 0.1 & 0.1 & 7.3 & 13.3 & 0.3 & 5.3 \\
\hline $6-8$ & 4.4 & 0.5 & 16.8 & $*$ & * & 0.2 & 0.9 & 0.1 & 1.3 \\
\hline $8-10$ & 1.1 & $*$ & 1.0 & $*$ & $*$ & $*$ & $*$ & * & 0.6 \\
\hline $10-12$ & 0.3 & $*$ & 0.1 & $*$ & * & $*$ & $*$ & $*$ & 0.2 \\
\hline$>12$ & * & $*$ & $*$ & $*$ & $*$ & $*$ & $*$ & $*$ & $*$ \\
\hline
\end{tabular}

* Contains less than $0.05 \%$ of the added Cs-134 activity.

additional effect of humus layer thickness/mineral material content of the humus layer are evident for all three precipitation types. This could be due to the lower density of organic rich layers and/or humus blocking specific clay mineral sites [8].

In contrast, the vertical distribution of "older" Cs-137 (mainly from the Chernobyl accident) was not largely affected by type of precipitation. Furthermore, no clear differences were found between the 9 treated ("columns") and 6 untreated ("references") profiles taken from the same $20 \mathrm{~m}^{2}$ sampling site. In both cases about $60 \%$ of the total activity was found in the uppermost $2 \mathrm{~cm}$, indicating that the main part of Cs-137 is now irreversibly fixed to this type of soil. This corresponds well with the findings of the field studies discussed above - with low mobile Cs fraction of area C. In view that the exchangeable fraction in area A was several times higher, it would have been interesting to study the results from a corresponding column study using soil from southernmost Norway.

\section{CONCLUSION}

Our study has demonstrated that chemical climate can have an impact on environmental behaviour of radioactive caesium: The field studies showed significant regional differences in plant uptake between the investigated areas e.g. with soil-to-plant transfer factors being up to 7-8 times higher for the sites receiving acid rain. Moreover, the main conclusion from the columns studies was that acid rain increases vertical movement of radioactive caesium compared with other types of precipitation typical for Norway. However, the importance of precipitation quality on soil depth distribution and plant uptake of radioactive caesium may depend on additional factors such as physical composition of the soil and time since fallout.

\section{Acknowledgments}

This work was financially supported by The Norwegian Research Council.

\section{References}

[1] Låg J. (1968). Relationships between the chemical composition of the precipitation and the content of exchangeable ions in the humus layer of natural soils. Acta Agric. Scand. 18 (1968): 148-152.

[2] Bjerk T., Steinnes E. and Varskog P. Retention of radiocesium in natural topsoil in Norway. The Fourth International Conference on Environmental Radioactivity in the Arctic - Edinburgh, 20-23 September 1999, 213-215. 
[3] Steinnes E. and Gjelsvik R. Geographical trends in Cs-137 fallout from the Chernobyl accident and leaching from natural surface soil in Norway. International Conference on Radioecology and environmental radioactivity - Bergen 15-20 June 2008, P. Strand, J. Brown, T. Jølle (eds), 214-217.

[4] Henriksen A. Norwegian institute of water research, personal communication (2007).

[5] Steinnes E., Rambæk J.P. and Hanssen, J.E. Large scale multi-element survey of atmospheric deposition using naturally growing moss as biomonitor. Chemosphere 25 (1992): 735-752.

[6] Backe S., Bjerke H., Rudjord A. L., Ugletveit F. Fall-out patterns in Norway after the Chernobyl accident estimated from soil samples. Rad. Prot. Dosimetry 18 (1987): 105-107.

[7] Backe S., Bjerke H., Rudjord A. L., Ugletveit F. Cesium fallout in Norway after the Chernobyl accident. Østerås:National Institute of Radiation Hygiene, SIS Rapport 1986:5 (1986) (in Norwegian), .

[8] Rigol A., Vidal M., Rauret G. (2002). An overview of the effect of organic matter on soil radiocaesium interaction: implications in root uptake. J. Environ. Radioact. 58: 191-216. 